\title{
Distribution of heavy metals and metalloid in surface sediments of heavily-mined area for bauxite ore in Pengerang, Malaysia and associated risk assessment
}

\begin{abstract}
A detailed investigation has been conducted to evaluate the distribution of heavy metals and metalloid in the surface sediments of a bauxite mining area in association with the potential ecological and human health risk. Field sampling was carried out within the Pengerang bauxite mining areas, including mine tailings, ex-mining pond and streams. Distribution of heavy metals ( $\mathrm{Al}, \mathrm{Cd}, \mathrm{Co}, \mathrm{Cr}, \mathrm{Cu}, \mathrm{Fe}, \mathrm{Mn}, \mathrm{Pb}, \mathrm{Sr}, \mathrm{Zn}$ ) and metalloid such as As in sediments indicated that $\mathrm{Fe}$ and $\mathrm{Al}$ constituted the greatest portion of metal elements in the sediment while $\mathrm{Pb}$ and $\mathrm{Cu}$ were found exceeding the recommended guideline values at some locations. Assessment of potential ecological risk (PERI) demonstrated low to medium ecological risk in the metal-contaminated sediments with $\mathrm{Cd}$, As and $\mathrm{Pb}$ have generally greater risk compared to other metals, contributing the most to the total risk index (RI). The sediment enrichment factor (EF) indicated no enrichment of most metals while $\mathrm{Pb}$ and $\mathrm{As}$ at some locations were classified as having minor and moderately to severe enrichment. The geo-accumulation index (Igeo) and contamination factor (CF) indicated that the sediments were classified uncontaminated with respect to most metals. Assessment of potential human health risk revealed that the hazard index (HI) values of the carcinogenic and noncarcinogenic risks were an order of magnitude higher among children compared to adults. There were no significant non-carcinogenic risk due to metals and metalloid in the study area as HIs < 1 . However, the lifetime cancer risk (LCR) for As is relatively higher than other metals and falls within tolerable LCR for regulatory purposes. Therefore, this study has highlighted the implication on potential ecological and human health risks of heavy metal occurrence in sediments of bauxite mining areas thus indicating the importance of geomorphological changes due to land exploitation for mining sector.
\end{abstract}

Keyword: Bauxite; Mining sediment; Heavy metals; Geochemical indices; Potential ecological risk; Human health risk 